\title{
Exhaustive in vivo labelling of plasmid DNA with BrdU for intracellular detection in non-viral transfection of mammalian cells
}

\begin{tabular}{|c|c|}
\hline Journal: & Biotechnology Journal \\
\hline Manuscript ID: & biot.200900053.R1 \\
\hline Wiley - Manuscript type: & Research Article \\
\hline $\begin{array}{r}\text { Date Submitted by the } \\
\text { Author: }\end{array}$ & 15-May-2009 \\
\hline Complete List of Authors: & $\begin{array}{l}\text { Jérôme, Valérie; University of Bayreuth, Chair for Process } \\
\text { Biotechnology } \\
\text { Heider, Andreas; University of Bayreuth, Chair for Process } \\
\text { Biotechnology } \\
\text { Schallon, Anja; University of Bayreuth, Chair for Process } \\
\text { Biotechnology } \\
\text { Freitag, Ruth; University of Bayreuth, Chair for Process } \\
\text { Biotechnology }\end{array}$ \\
\hline Keywords: & $\begin{array}{l}\text { DNA detection, gene delivery, 5-bromodeoxyuridine, in vivo } \\
\text { labelling, transfection }\end{array}$ \\
\hline
\end{tabular}

\section{scholarONE" \\ Manuscript Central}




\title{
Research Article ((5784 words))
}

Exhaustive in vivo labelling of plasmid DNA with BrdU for intracellular detection in non-viral transfection of mammalian cells

\author{
Valérie Jérôme, Andreas Heider, Anja Schallon, and Ruth Freitag* \\ Chair for Process Biotechnology, University of Bayreuth, Germany \\ *corresponding author: Chair for Process Biotechnology, University of Bayreuth, 95440 \\ Bayreuth, Germany, phone: 0049921 55-7371, Fax: 0049921 55-7375, e-mail: \\ bioprozesstechnik@uni-bayreuth.de
}

\section{Keywords:}

DNA detection, gene delivery, 5-bromodeoxyuridine, in vivo labelling, transfection 


\begin{abstract}
The study of the non-viral gene delivery process at the molecular level, e.g. during the transfection of mammalian cells, is currently limited by difficulties to specifically detect the transfected plasmid DNA within the cells. Herein we describe the in vivo production of 5-

bromodeoxyuridine- (5-BrdU) labelled plasmid DNA by a thymine-requiring Escherichia coli strain leading to $92 \pm 15 \%$ BrdU incorporation while minimizing plasmid structure alteration. The labelled plasmid is produced in the milligram scale in a two-stage cultivation process. The relevance of this approach for plasmid DNA visualization in the field of gene delivery is demonstrated by localising the BrdU-labelled plasmid DNA via immunodetection / fluorescence microscopy in CHO-K1 cells after electroporation with naked, BrdU-labelled plasmid DNA and after polyfection with PEI/BrdU-labelled plasmid complexes.
\end{abstract}




\section{Introduction}

The genetic modification of mammalian cells can be achieved by a number of viral and nonviral methods. Viral transfection is orders of magnitude more efficient and therefore preferred in genetic medicine, i.e. for gene delivery to multicellular organisms. The typical application in biotechnology, i.e. the genetic modification of eukaryotic (mammalian) cells for the creation of the recombinant production organism, on the other hand, relies almost exclusively on non-viral methods, mainly due to a superior safety profile and the possibility to deliver much larger amounts of DNA. A variety of non-viral gene delivery methods for mammalian cells has been used successfully for years, including inter alia electroporation and transfection via complexation of the DNA with the polycation PEI (polyethylenimin). However, some questions remain open, in particular in regard to the events between the first entry of the DNA (the complexes) into the cell and the final integration of the transfected DNA into the genomic DNA of the host cell. Answers to these questions could help to identify hitherto unknown bottlenecks of non-viral transfection and eventually help to improve the performance of such methods, thereby improving the efficiency of process development in mammalian cell culture technology.

Difficulties in the specific detection of the transfected plasmid DNA (pDNA) in the cells represent an important limitation for the study of the gene transfer process. So far, only a limited number of studies have been reported where the transfected pDNA was directly visualized. The majority of these studies used intercalating or fluorescent dyes for labelling the pDNA preliminary to transfection $[1,2]$. It has been recognized, however, that such labels will inevitably modify the polarity of the plasmid and thus potentially alter its intracellular trafficking as has, e.g., been shown for the Hoechst 33258 dye [3].

The thymidine analogue 5-bromodeoxyuridine (BrdU) can specifically replace the thymidine residue in DNA molecules [4]. An immunoenzymatic detection procedure, based on the use of 
a monoclonal antibody specific for 5-bromodeoxyuridine (BrdU), has been described for BrdU-labelled DNA in DNA-DNA and DNA-RNA hybridization assays involving BrdUlabelled probes [5, 6]. BrdU labelling of genomic DNA has also been used as a tool for assessing metabolic activity in mammalian cells and tissues via DNA synthesis [7] under conditions where low amounts of the label are integrated into the genomic DNA. The in vivo incorporation of BrdU into plasmid DNA by E. coli was first proposed by Kitazawa [8] leading to a substitution of approximately $80 \%$ of $\mathrm{T}$ by BrdU. According to the authors, the labelled plasmid could later be used as probe for hybridization after restriction endonuclease digestion. El Ouahabi and colleagues labelled small amounts of plasmid DNA using a modified nicktranslation protocol and demonstrated that BrdU-labelling can be a useful tool to visualize exogenous DNA after transfection [9].

Herein we describe an improved method for the in vivo production of BrdU-labelled plasmid DNA in a thymidine-requiring Escherichia coli strain, leading to $92 \pm 15 \%$ BrdU incorporation. Labelled plasmid DNA was produced at the milligram scale using a two-stage growth/production process. The possible relevance of this system for investigating intracellular events during gene delivery is demonstrated by visualising BrdU-labelled pDNA within the cytoplasm of Chinese Hamster Ovary $(\mathrm{CHO})$ cells after electroporation and polyfection using polyethyleneimine (PEI) as transfection agent.

\section{Materials and Methods}

Materials. Chemicals were from established suppliers such as Sigma-Aldrich and used as obtained. Milli-Q ${ }^{\mathrm{TM}}$ water was used for the preparation of all aqueous solutions. PEI (branched, $25 \mathrm{kDa}$, Sigma) was prepared as $10 \mu \mathrm{M}$ aqueous solution in Milli- $\mathrm{Q}^{\mathrm{TM}}$ water. The primary monoclonal anti-BrdU antibodies were from Invitrogen (clone IU-4) and from Sigma (clone BU33). The secondary antibodies were either a goat anti-mouse IgG conjugated to R- 
PE (R-phycoerythrin, Invitrogen, immunofluorescence studies) or a rabbit anti-mouse IgG antibodies conjugated to HRP (horse radish peroxidase, Dako, dot-blot).

\section{Fluorescence labelling of PEI}

For fluorescence labelling of the transfection agent PEI, a method adapted from Godbey et al. was used [1]. For labelling with Rhodamin Red (Molecular Probes), branched PEI was dissolved at a concentration of 10 $\mathrm{mg} / \mathrm{mL}$ in a $0.1 \mathrm{M}$ aqueous solution of $\mathrm{NaHCO}_{3}$. A 1-mL PEI aliquot was then transferred to a microcentrifuge tube. While shaking, $61.5 \mu \mathrm{L}$ of the fluorochrome solution (rhodamine red X succinimidyl ester, in DMSO at $10 \mathrm{mg} / \mathrm{mL}$ ) was added; thereafter shaking was continued for 1 hour in the dark at room temperature. Then, the samples were further incubated for 1 hour in the dark without agitation. The residual non-incorporated fluorochrome was removed by chloroform extraction. The labelled PEI was stored at $4{ }^{\circ} \mathrm{C}$ protected from light until use. The protocol for labelling with Cascade Blue (Molecular Probes) was similar. However, only $48.5 \mu \mathrm{L}$ of dye (10 mg/mL in DMSO) were added, while residual dye was removed by ultrafiltration (centrifugation, $1.5 \mathrm{~mL}$ Microcon YM-3 tube, membrane: regenerated cellulose MCO 3000 Da, 2 washings with Milli-Q water) instead of chloroform extraction.

Plasmids $\quad \mathrm{pH}_{2} \mathrm{~B}-\mathrm{GFP}$ [10], encoding for the nuclei localized green fluorescent protein (GFP), was used for the experiments. All plasmids were amplified in E. coli chi 1776 strain, in 394 medium or in 394-BrdU medium (see below) to sufficient quantities by using standard molecular biology techniques, including harvesting and purification via Qiagen Plasmid Midi-kit (Qiagen). DNA concentration and quality were determined by $\mathrm{OD}_{260} / 280$ ratio and by agarose gel electrophoresis (topoisomers and restriction pattern).

Bacteria strain and culture conditions. The thymidine-requiring Escherichia coli chi-1776 (DMS 3804) strain was obtained from the DSMZ (German Collection of Microorganisms and Cell Cultures). Cells were grown in '394 medium' (LB medium supplemented with $5 \mathrm{mM}$ $\mathrm{MgCl}_{2}, 0.01 \%$ diaminopimelic acid, $0.5 \%$ glucose, and $40 \mathrm{mg} / \mathrm{L}$ thymidine) at $37{ }^{\circ} \mathrm{C}$. For 
BrdU labelling, $40 \mathrm{mg} / \mathrm{L}$ BrdU was added to the medium instead of the thymidine ('394-BrdU medium').

Cell culture. The Chinese Hamster Ovary cells (cell line CHO-K1, CCL-61, ATCC) were maintained in growth medium (RMPI 1640 medium supplemented with L-glutamine, penicillin/streptomycin and $10 \%$ foetal calf serum (FCS); all from PAA laboratories) in an atmosphere of $5.0 \% \mathrm{CO}_{2}$ and at $37^{\circ} \mathrm{C}$.

Transfection. Cells were seeded on cover slips, at $2 \times 10^{5}$ cells per well in 6-well plates (Greiner) $24 \mathrm{~h}$ before transfection. One hour before transfection, cells were rinsed with PBS (0. $137 \mathrm{M} \mathrm{NaCl}, 1.47 \mathrm{mM} \mathrm{KH}_{2} \mathrm{PO}_{4}, 2.68 \mathrm{mM} \mathrm{KCl}, 8.1 \mathrm{mM} \mathrm{Na}_{2} \mathrm{HPO}_{4}, \mathrm{pH}$ 7.4) and supplemented with fresh serum-reduced culture medium OptiMEM/Glutamax (Gibco). $3 \mu \mathrm{g}$ plasmid DNA were diluted to $300 \mu \mathrm{L}$ in $150 \mathrm{mM} \mathrm{NaCl}$ and vortexed. Then, $9.9 \mu \mathrm{L}$ of PEI solution $(10 \mu \mathrm{M})$ was added to the pDNA- $\mathrm{NaCl}$ solution, which was the vortexed and incubated for $10 \mathrm{~min}$ at room temperature for complex formation. Thereafter, the PEI/DNA complexes were added to the cells (time 0$)$ and the plates were briefly centrifuged $(200 \mathrm{~g}, 5 \mathrm{~min}$, $4{ }^{\circ} \mathrm{C}$ ). The cells were incubated at $37^{\circ} \mathrm{C}$ and $5 \% \mathrm{CO}_{2}$ for 4 hours, at which time the medium was replaced with $2 \mathrm{~mL}$ of RPMI-10 \% FCS. Incubation was continued until the indicated time. Note: cells that were evaluated at time points shorter than 4 hours did not receive a medium replacement after transfection.

For electroporation, the cells were suspended in cold RPMI 1640 without FCS at a density of $2 \times 10^{7}$ cells $\mathrm{mL}^{-1}$. A volume of $0.25 \mathrm{~mL}$ was transferred to a sterile electroporation cuvette (Thermo Electro Corporation, 50 x $4 \mathrm{~mm}$ ) and $20 \mu \mathrm{g}$ plasmid DNA in $250 \mu \mathrm{L}$ RPMI 1640 was added to the cells. After 10 min incubation at room temperature, the aliquot was electroporated using a Bio-Rad Gene Pulser-Transfection Apparatus at $500 \mu \mathrm{F}$ and $300 \mathrm{~V}$. After receiving the electric pulse, the cells were incubated in the cuvette for $10 \mathrm{~min}$ at $37^{\circ} \mathrm{C}$ before 
being transferred to 6 -well plates (Greiner) and incubated until the indicated time at $37{ }^{\circ} \mathrm{C}$ in a humidified atmosphere of $5 \% \mathrm{CO}_{2}$.

\section{Labelling of DNA with 5-bromodeoxyuridine A single colony of Escherichia} coli chi-1776 strain containing $\mathrm{pH}_{2} \mathrm{~B}-\mathrm{GFP}$ plasmid DNA was inoculated in $15 \mathrm{~mL} 394$ medium. The culture was grown overnight under vigorous shaking (180 rpm) and the bacteria were diluted to $\mathrm{OD}_{600}=0.3$ and again grown in the thymidine-containing medium at $37{ }^{\circ} \mathrm{C}$ under vigorous shaking until $\mathrm{OD}_{600}=1.3$ was reached. Thereafter, the bacteria were recovered by centrifugation ( $10 \mathrm{~min}, 4^{\circ} \mathrm{C}, 4300 \mathrm{rpm}$, centrifuge: Heraeus $2 \mathrm{LR}$ ), washed once with 394-BrdU medium (resuspension/centrifugation as above), and finally resuspended in 394BrdU medium at a $\mathrm{OD}_{600}=0.3$, and grown at $37^{\circ} \mathrm{C}$ under vigorous shaking overnight. After harvesting and lysing the bacteria, closed circular plasmid DNA was purified using a commercial plasmid purification kit (Qiagen) according to the manufacturer's instructions.

Dot-blot detection of BrdU For the detection of BrdU incorporated in DNA by dot-blot, a modified protocol of the method proposed by Ueda et al. [11] was used. Briefly, $2 \mu \mathrm{g}$ DNA was denatured by incubation with 10 volumes of $0.4 \mathrm{M} \mathrm{NaOH}$ for $30 \mathrm{~min}$ at room temperature. The DNA solution was then placed on ice and neutralized by an equal volume of $1 \mathrm{M}$ Tris $\mathrm{HCl}$ (pH 6.8). 15 to $450 \mathrm{ng}$ of single-stranded neutralized DNA was spotted onto an Optitran BA-S 83 nitrocellulose membrane (Schleicher and Schuell). The filters were dried at room temperature and then baked for $2 \mathrm{~h}$ at $80{ }^{\circ} \mathrm{C}$ under vacuum. Afterwards, the membrane was incubated with the anti-BrdU antibody (1:2,000 dilution, clone IU-4) in TBS-T (20 mM Tris $\mathrm{HCl}, \mathrm{pH}$ 7.6, $136 \mathrm{mM} \mathrm{NaCl}, 0.05 \%$ Tween 20, containing $1 \%$ nonfat milk) for $1 \mathrm{~h}$ at room temperature. Excess antibody was removed by washing three times with TBS-T. The membrane was incubated with an anti-mouse IgG-HRP antibody (1: 5,000 dilution in TBS-T) for 1 $\mathrm{h}$ at room temperature. The membrane was then washed three times (20 min each) with TBS$\mathrm{T}$, and the substrate for alkaline phosphatase $(1 \mathrm{mg} / \mathrm{mL} \mathrm{DAB}(3,3$-diaminobenzidine $)$ in 50 
$\mathrm{mM}$ Tris - $\mathrm{HCl}$, $\mathrm{pH} 7.6$, containing $0.6 \% \mathrm{H}_{2} \mathrm{O}_{2}$ ) was added for an incubation of 5 to $10 \mathrm{~min}$ in the dark. The enzyme reaction was stopped by washing the membrane in Milli- $\mathrm{Q}^{\mathrm{TM}}$ water. Afterward, the blot was scanned and signal intensities analyzed using the integrated density function in ImageJ [12]. For detection of the BrdU-pDNA in the polyplex, the PEI/DNA complex was treated as described above for the naked pDNA and volumes corresponding to 15 to 450 ng pDNA were blotted on the membrane. Further treatment was as described above. Polyplexes were in addition subjected to an 'acidic' denaturation protocol, in analogy to the one described below for intracellular DNA. For this polyplexes were incubated (after fixation in $4 \%$-formaldehyde or not) for $30 \mathrm{~min}$ at room temperature in $0.5 \%$ Triton X100 / $2 \mathrm{M}$ $\mathrm{HCl}$. The acid was neutralised by sufficient amounts of $1 \mathrm{M}$ Tris $\mathrm{HCl}$ and the subsequent treatment was as described above.

In order to quantitate BrdU incorporated in the pDNA, the dot blot was calibrated as follows. Firstly a PCR product with $100 \%$ substitution of T by BrdU was prepared as described below. In addition, the corresponding unlabelled PCR product was prepared using the GFP cDNA as template. The PCR reaction in both cases used the specific primer pair: forward primer: 5'TCCCCCGGGGGATTATTTGTAGAGCTCATCCAATGCCATGTG-3'; reverse primer: 5'TCCCCCGGGGGAGCATGGTAGCAAAGGAGAAGAACTTTTCAC-3'). 50 L PCR mixture containing 1 x Taq Pol buffer, $0.20 \mathrm{mM}$ of dATP, dCTP, dGTP and either dTTP or BrdUTP, and $1 \mathrm{U}$ Taq polymerase (New England Biolabs GmbH), as well as $0.5 \mu \mathrm{M}$ of each primer were combined with $1.0 \mu \mathrm{L}$ DNA solution $(1 \mathrm{ng} / \mu \mathrm{L})$. Sterile water was used as no template control. The temperature programme for the PCR consisted of one denaturation step at $95{ }^{\circ} \mathrm{C}$ for $5 \mathrm{~min}, 35$ cycles of $95{ }^{\circ} \mathrm{C}$ for $1 \mathrm{~min}, 63{ }^{\circ} \mathrm{C}$ for $1 \mathrm{~min}$, and $72{ }^{\circ} \mathrm{C}$ for $1 \mathrm{~min}$, and a final extension step at $72{ }^{\circ} \mathrm{C}$ for $10 \mathrm{~min}$.

The PCR products were purified using a commercial purification kit ("wizard plus SV mini columns" kit; Promega) according to the manufacturer's instructions. All PCR products were 
evaluated by agarose gel electrophoresis after purification and the DNA concentration was estimated by measuring the absorption at $260 \mathrm{~nm}$. For calibration of the dot blot, the indicated amounts (15-450 ng) of PCR product containing either thymidine or BrdU were dot-blotted on a nitrocellulose membrane (see below for the protocol) and the incorporated BrdU was immunochemically visualized. The calibration curve was prepared from 6 concentration points, each measured five times. Means and standard deviations were calculated and formed the basis for a weighed regression.

Intercellular detection of BrdU via immunofluorescence For detection of BrdU-containing DNA inside the cells, cells were washed twice with PBS and then fixed in $4 \% p$ formaldehyde/PBS for $20 \mathrm{~min}$ at room temperature. After fixation, cells were incubated in $0.5 \%$ Triton $\mathrm{X} 100 / 2 \mathrm{M} \mathrm{HCl}$ for $30 \mathrm{~min}$ at room temperature. Cells were washed three times for 5 min with PBS and incubated for $30 \mathrm{~min}$ at $37^{\circ} \mathrm{C}$ in the blocking buffer (PBS containing $0.5 \%$ Tween 20 and $0.5 \%$ BSA). Then the cells were incubated with the anti-BrdU antibody (1:160 dilution; clone BU33) in blocking buffer for $1 \mathrm{~h}$ at RT. After three 5-min washes with PBS, the cells were incubated with the anti-mouse IgG-RPE (diluted 1:200 in blocking buffer supplemented with $1 \mathrm{mg} / \mathrm{L}$ Hoechst 33258) for $1 \mathrm{~h}$ at room temperature. Cells were then washed twice for 5 min with PBS-T and once with Milli-Q water. The cover slips were mounted in Prolong Gold (Invitrogen) mounting medium. Cells were observed under an epifluorescence microscope (Olympus BX51TF). In addition, images were obtained using a laser scanning confocal microscope (Leica TCS-SP) equipped with argon and neon lasers (Leica). Serial images of rhodamine fluorescence at $0.16 \mu \mathrm{m}$ Z-intervals were recorded separately. Images were further analyzed using Bioview 3D software [13].

\section{Results and discussion}

\section{5-BrdU incorporation into pDNA.}


For pDNA labelling with 5-bromouracil (replacement of $\mathrm{T}$ by $\mathrm{BrdU}$ ), the thymidine-requiring Escherichia coli chi-1776 strain was to be used. Since this strain is described to preferentially grow at $30{ }^{\circ} \mathrm{C}[14]$, preliminary experiments were performed to compare the growth of this microorganism at 30 and $37^{\circ} \mathrm{C}$. In our hands, decreasing the culture temperature did not improve, but rather reduced the growth rate (data not shown). Thus, we opted for performing further experiments at $37^{\circ} \mathrm{C}$.

The in vivo labelling of plasmid DNA (pDNA) with the thymidine analogue BrdU has been, to our knowledge, described only once in the literature [8]. In that case, the authors used large amount of the thymidine analogue $\mathrm{BrdU}$ (500 mg/L culture medium) corresponding to 8- to 60-fold higher quantity than used by other groups for genomic labelling [e.g. 15, 16]. According to the authors, an incorporation of BrdU in $15-20 \%$ of the total DNA was achieved, corresponding to the substitution of approximately $80 \%$ of $\mathrm{T}$ by BrdU.

In our hands, cultivation of T-requiring E. coli (strain Escherichia coli chi-1776, containing plasmid $\mathrm{pH}_{2} \mathrm{~B}$-EGFP) for 5 to 16 hours in a medium containing BrdU (concentration range from 40 to $120 \mathrm{mg} / \mathrm{L}$ ) instead of thymidine, resulted in significantly retarded growth and led to cell densities ten-fold lower than in the case of the positive control (bacteria cultivated in the presence of T), see Table 1. Bacterial growth is thus not supported in the presence of only BrdU instead of T. Moreover, even in the presence of regular amounts of thymidine (40 $\mathrm{mg} / \mathrm{L}$ ), the addition of more than $40 \mathrm{mg} / \mathrm{L}$ of BrdU was detrimental to bacterial growth, Table 1 , most likely due to blockage of the replicative and transcriptional machinery in the presence of a surplus of BrdU over $\mathrm{T}$ in the medium. When $40 \mathrm{mg} / \mathrm{L}$ or less of BrdU were added in the presence of $40 \mathrm{mg} / \mathrm{L} \mathrm{T}$, overnight growth appeared normal, Table 1. Similarly, growth could be initiated in cultures originally grown in the presence of $40 \mathrm{mg} / \mathrm{L}$ of BrdU by the addition of $40 \mathrm{mg} / \mathrm{L}$ of thymidine, allowing the conclusion that such amounts of BrdU do not support growth, but are otherwise non-toxic for the bacteria. The discrepancy between our results and 
the published data [8] may be due to the use of different strains of bacterial, as the bacterial strain used was unfortunately not specified in the previous publication. On the other hand, our results are in agreement with the data published by Hackett and Hanawalt [16], which described a marked preference of a thymidine requiring bacteria strain for thymidine over BrdU.

Based on the facts that low amounts of BrdU were not toxic to the bacteria and that limited growth in the presence of BrdU was apparently possible, the following two-stage protocol was derived for in vivo labelling of pDNA with BrdU. The bacteria were first grown in the standard thymidine-containing medium until the mid-exponential phase was reached ('growth phase'). At this point $\left(\mathrm{OD}_{600} \approx 1.3\right)$, the bacteria were recovered and resuspended at $\mathrm{OD}_{600}=$ 0.3 in the BrdU medium ('labelling phase') where they were again allowed to grow overnight. Compared to direct cultivation in BrdU medium, this new protocol led to bacteria concentrations at the end of the culture $\left(\mathrm{OD}_{600}=2.40\right)$, which were similar to cell densities obtained in case of cultivations in the standard thymidine-containing medium. The two-stage process was scaled up to $100 \mathrm{~mL}$ and allowed the preparation of up to $10 \mu \mathrm{g}$ of BrdU-pDNA per mL of bacterial culture at high purity $\left(\mathrm{OD}_{260 / 280}\right.$ ratio: 1.98$)$. Average yields for the BrdU-labelled pDNA were thus approximately $70 \%$ of those obtained for unlabelled pDNA prepared by the standard procedure. Finally, we confirmed by analysis on agarose gel that the incorporation of BrdU into the pDNA did not influence the content of the supercoiled topoisomer in the plasmid preparation or the restriction pattern (data not shown).

Quantitation of the BrdU-labelling index by dot-blot.

For assessment of the BrdU-labelling index of the prepared pDNA, a dot-blotting technique was adapted that had previously been described as accurate and efficient for proliferation DNA quantitation in animal tissues [11]. In particular, we amplified the GFP cDNA by PCR in the presence of BrdUTP instead of dTTP. This experimental set up assured $100 \%$ substitution of $\mathrm{T}$ by BrdU in the PCR product. In addition, standard PCR products and plasmids were 
produced (containing only $\mathrm{T}$ and no BrdU) and used as negative control. Various amounts of the BrdU-labelled PCR product (0-454 ng, 6 concentrations, each $n=5)$ were dot-blotted onto nitrocellulose membranes, and the incorporated BrdU was quantified by immunoenzymatic detection, Figure 1a, to create a calibration curve, Figure 1b. The BrdU signal intensity increased in a linear fashion with an increasing amounts of dot-blotted labelled DNA (weighed linear regression: $\left.\mathrm{y}=2.41 \times 10^{7} \log _{10}(\mathrm{x})-3.12 \times 10^{8} ; \mathrm{R}^{2}=0.970, \mathrm{n}=5\right)$, demonstrating that this method is applicable for quantitative analyses. Standard deviations for the different concentrations - save for the very lowest concentration - were all below $15 \%$, which is quite satisfactory given the semi-quantitative nature of the dot blot method in general. No signal was obtained from the negative controls. In addition, this method is fairly sensitive for detecting BrdU signals, since as little as $30 \mathrm{ng}$ of PCR product per dot could be reliably detected.

On the basis of these results, 0 to $454 \mathrm{ng}$ of pDNA isolated from bacteria grown on BrdU medium were dot-blotted in duplicate to quantitate the substitution of $\mathrm{T}$ by BrdU and to calculate the BrdU-labelling index. For this purpose, the quantity of applied DNA was converted into thymidine units and the amount of BrdU-units was determined by dot-blotting and subsequent densitometric analysis. According to these measurements, the labelling protocol described in this work achieves a BrdU-labelling index of $92 \pm 15 \%$.

Subsequently, quantitation of BrdU-pDNA compacted in polyelectrolyte complexes with the polycation PEI was attempted via the dot-blot method. However, in this case no signal was obtained. This was not due to failure of the PEI/DNA-complex to bind to the membrane, since in cases where Rhodamine-labelled PEI was used to complex the DNA, the polymer could be shown to bind quantitatively to the membrane and to stay there throughout the required manipulations. However, as Ueda et al. showed, the anti-BrdU antibody preferentially binds to single-stranded DNA and denaturation is therefore essential for the dot-blotting method [11]. In the protocol suggested by this author and used by us, denaturation is achieved by strongly 
alkaline $\mathrm{pH}(\geq 12)$. Since PEI is known to have a considerable buffering capacity over a wide $\mathrm{pH}$-range $[17,18]$, we first verified that the $\mathrm{pH}$ during the denaturation step was in the required $\mathrm{pH}$ range, which was the case. Our inability to detect pDNA could thus only have been due to a complete loss of the DNA, e.g. during the washing steps, which is difficult to imagine even though at pH 12 PEI will be mostly neutralised, i.e. less able to compact the DNA, or quite the contrary - due to the fact that in spite of its likely denaturation, the pDNA strands remain so tightly compacted in the polyplex that they are in fact inaccessible to the antibody similar to the situation in double stranded DNA. In case of PEI-DNA polyplexes containing native DNA it has, e.g. been shown that compaction can be tight enough to prevent the insertion of intercalating dyes such as ethidium bromide. Thus, in order to exclude that our failure to detect the pDNA was due to the unsuitability of the alkaline denaturation step, we combined the dot blot assay with an acidic denaturation step similar to the one used below for the intracellular detection of BrdU-labelled pDNA, but were again unable to detect our pDNA within the polyplexes.

\section{Intracellular detection of BrdU-labelled plasmid DNA in the cytosol of mammalian cells}

In order to investigate the potential of the BrdU-labelling method for localising the DNA inside mammalian cells, naked BrdU-pDNA, namely BrdU-labelled $\mathrm{pH}_{2} \mathrm{~B}$-EGFP, was electroporated into $\mathrm{CHO}$ cells. Three hours post electroporation, the cells were fixed with $4 \% p$ formaldehyde, and treated with a permeabilisation solution (0.5\% Triton X100 / $2 \mathrm{M} \mathrm{HCl})$, prior to staining with the anti-BrdU antibody/detection antibody pair (anti-BrdU antibody; clone BU33, detection antibody: anti-mouse IgG-RPE). Then the preparation was analysed by fluorescent microscopy. Positive staining appeared in the cytoplasm, see e.g. Figure 2, panel B. To verify the specificity of the detection for BrdU-labelled pDNA, several controls of the protocol were carried out. When the acid treatment or the primary antibody was omitted, no fluorescence could be detected in the cell. Likewise, non-transfected cells or cells transfected 
with non-labelled plasmid DNA did not give rise to any specific fluorescence signal. To further confirm the specificity of the anti-BrdU antibody detection, BrdU was incorporated into the nuclear DNA of the CHO cells by metabolic labelling and the cells were stained as described above. In this case, the fluorescence was found exclusively within the nuclei.

Concerning the localisation of the electroporated BrdU-pDNA, Figure 2, fluorescence was associated with aggregates of homogeneous size that might represent some accumulation of the labelled pDNA within small vesicles. Additionally, larger aggregates could be seen, indicated by an arrow in Figure 2, panel B, which could typically be resolved into several small aggregates by analysing the slide with phase contrast. In none of the experiments with cells 3 h post electroporation was BrdU-labelled pDNA ever found inside the nucleus. Analyses of cells $6 \mathrm{~h}, 12 \mathrm{~h}$, and $24 \mathrm{~h}$ post electroporation also gave no evidence for the presence of BrdUlabelled pDNA in the nuclei. While this could indicate an inability of the labelled pDNA to enter the nucleus, it is in view of the generally low efficiency of non-viral transfection methods more likely that the concentration of labelled pDNA inside the nucleus was simply below the detection limit of our method. It is also possible that the pDNA in the nuclei becomes masked to the antibody, e.g. due to an interaction with chromatin or some components of the transcription machinery. Incidentally, the one other work published on using BrdU-labelled plasmid DNA also failed to detect the pDNA inside the nucleus [9]. In order to gain additional information on the cellular localisation of the BrdU-pDNA, we re-analysed the slides with a laser confocal microscope (LSM). The LSM-analysis confirmed the exclusive cytoplasmic localisation of the plasmid, Figure 3, panel A.

The indirect proof of entry into the nucleus via the expression of the reporter gene was also not possible in case of the BrdU-labelled plasmid, since expression was not observed in these cases. However, when the unlabelled plasmid was used under otherwise similar transfection conditions, expression of the reporter gene (GFP) was seen as early as two hours post electro- 
poration. The pronounced similarity between thymidine and the analogue BrdU argues against major differences in nuclear uptake of the two types of polynucleotide. In our opinion the lack of expression in case of the BrdU-labelled pDNA is more likely due to an incompatibility with the transcription machinery, as discussed above for the lack of bacterial growth in a culture medium supplemented with BrdU instead of thymidine.

In order to localise the pDNA in the cells after polyfection, BrdU-pDNA was complexed with PEI and fluorescent dye-labelled PEI respectively and incubated with the $\mathrm{CHO}$ cells for various times (ranging from 0.3 to $3 \mathrm{~h}$ ). Since in vitro we had been unable to detect BrdU-labelled pDNA in the polyplexes, we expected to be reduced to seeing only the labelled PEI inside the cells, not the pDNA. To our surprise however, intracellular detection of BrdU-pDNA after polyfection was possible, Figure 2, panel D, albeit at a weaker signal than in case of the naked BrdU-pDNA after electroporation, Figure 2, panel B. This may be due to the fact that a different primary and secondary antibody pair was used in the dot blot and the intracellular analysis of the polyplexes. More likely, however, is a general destabilisation of the complex in the cytosol under transfection conditions leading to a better exposure of the BrdU in the pDNA to the antibody. The fact that it was not the $p$-formaldehyde fixation / cell permeabilisation step that lead to the difference in detectability was ascertained by repeating the dot blot analysis of the polyplexes including a mock fixation step (in combination with acidic denaturation / 'permeabilisation'). Again no signal was obtained.

Finally, in order to simultaneously visualize both the transfection agent PEI and the pDNA, CHO cells were incubated with polyplexes made from cascade-blue-labelled PEI and BrdUpDNA. When the fluorescence distribution inside the cells was analyzed by fluorescence microscopy, PEI was indicated by fluorescent light in the blue region, while pDNA gave rise to red fluorescence. However, in these experiments no clear evidence for co-localization of the two molecules could yet be found, in particular not in the aggregates around the nuclei. It re- 
mains to be seen whether this is indeed indicative of complex dissociation in the cytosol or an artefact produced by the experimental conditions, in particular during fixation and denaturation.

\section{Conclusions}

Exhaustive labelling of in vivo synthesized pDNA with the thymidine analogue 5bromodeoxyuridine- $(5-\mathrm{BrdU})$ is possible using the two-stage protocol outlined in this contribution. The procedure leads to high T-substitution and has minimal influence on the structure and the restriction map of the plasmid product. Purification procedures are the same as those for non-labelled pDNA. The method contains no step that would prevent scale up to the bioreactor scale and hence constitutes a cheap and easy way of producing large quantities of labelled pDNA. This is a considerable improvement, e.g., in comparison to the nick-translation method proposed by El Ouahabi et al. [9] for the same purpose.

Since BrdU is a close T-analogue, BrdU-labelled pDNA can be used to investigate intracellular localisation of DNA during non-viral transfection of mammalian cells with a minimum of bias. Moreover, the detection based on a R-PE-conjugated anti-BrdU monoclonal antibody is simple and highly specific for the target DNA. Any non-labelled DNA present in the sample would therefore not be detected and its presence could not interfere with the interpretation of the results. In addition, BrdU-labelling overcomes the common problems linked with direct labelling, e.g., with fluorescent dyes; such as the alteration of the structural (supercoiled) and physico-chemical (hydrophobicity) properties of the plasmid DNA. The sensitivity of the method is comparable to those based on of fluorescent nucleic acid labelling systems. In spite of its similar structure, however, BrdU-labelled pDNA is apparently not compatible with the transcription machinery of the cells, as the corresponding gene product normally was not detected in cultures transfected with the labelled pDNA. 


\section{Acknowledgements}

The authors would like to thank Prof. Willert-Porada (Chair for Materials Processing, University of Bayreuth) for access to the confocal microscope and Dipl.-Ing. Ingrid Otto (Chair for Materials Processing, University of Bayreuth) for training on this device. Dr. Judicael Parisot (Chair for Process Biotechnology, University of Bayreuth) kindly labelled the PEI for us. 


\section{References}

[1] Godbey W.T., Wu K.K., Mikos A.G., Tracking the intracellular path of poly(ethylenimine)/DNA complexes for gene delivery, Proc. Nat. Ac. Sci. USA, 1999, 96, $5177-5181$.

[2] Zabner J., Fasbender A.J., Moninger T., Poellinger K.A. et al., Cellular and Molecular Barriers to Gene Transfer by a Cationic Lipid, J. Biol. Chem., 1995, 270, 18997-19007.

[3] Fong, S., Liu Y., Heath T., Fong P., et al., Membrane-Permeant, DNA-Binding Agents Alter Intracellular Trafficking and Increase the Transfection Efficiency of Complexed Plasmid DNA, Molecular Therapy, 2004, 10(4), 706-718.

[4] Kriss, J. P., Revesz L., Quantitative studies of incorporation of exogenous thymidine and 5-bromodeoxyuridine into deoxyribonucleic acid of mammalian cells in vitro, Cancer Res, $1961,21,1141-147$.

[5] Traincard F., Ternynck T., Danchin A., Avrameas S., An immunoenzyme technic for demonstrating the molecular hybridization of nucleic acids, Ann Immunol., 1983, 134D(3), $399-404$.

[6] Dolbeare, F., Bromodeoxyuridine: a diagnostic tool in biology and medicine, Part III. Proliferation in normal, injured and diseased tissue, growth factors, differentiation, DNA replication sites and in situ hybridization, Histochem J, 1996, 28(8), 531-75.

[7] Leif R.C., Stein J.H., Zucker R.M., A short history of the initial application of anti-5BrdU to the detection and measurement of S phase, Cytometry A., 2004, 58(1), 45-52.

[8] Kitazawa S., Takenaka, A., Abe N., Maeda S., et al., In situ DNA-RNA hybridization using in vivo bromodeoxyuridine-labeled DNA probe, Histochemistry, 1989, 92, 195-199 . 
[9] El Ouahabi, A., Thiry M., Schiffmann S., Fuks R., et al., Intracellular Visualization of BrdU-labeled Plasmid DNA/Cationic Liposome Complexes, J. Histochem. Cytochem. 1999, 47(9), 1159-1166.

[10] Kanda, T., Sullivan K.F., Wahl G.M., Histone-GFP fusion protein enables sensitive analysis of chromosome dynamics in living mammalian cells, Current Biology, 1998, 8(7), $377-385$.

[11] Ueda J., Saito H., Watanabe H., Evers B.M., Novel and quantitative DNA dot-blotting method for assessment of in vivo proliferation, Am J Physiol Gastrointest Liver Physiol, 2005, 288, G842-G847.

[12] Abramoff M.D., Magelhaes, P.J., Ram, S.J., Image Processing with ImageJ, Biophotonics International, 2004, 11, 36-42.

[13] Fedorov D., Bioview 3d, Center for BioImage Informatics, UCSB, 2008

[14] Clark-Curtiss J.E., Curtiss R., 3rd: Analysis of recombinant DNA using Escherichia coli minicells, Methods Enzymol. 1983, 101, 347-62.

[15] Yamamoto, Y., Yoshisada F., Uracil-DNA Glycosylase Causes 5-Bromodeoxyuridine Photosensitization in Escherichia coli K-12, J Bacteriology, 1990, 172, 5278-5285.

[16] Hackett Jr. P., Hanawalt P., Selectivity for thymine over 5-bromouracil by a thyminerequiring bacterium, Biochim. Biophys. Acta, 1966, 123, 356-363.

[17] Tang M.X. ,Szoka F.C., The influence of polymer structure on the interactions of cationic polymers with DNA and morphology of the resulting complexes,. Gene Therapy 1997, 4, $823-832$.

[18] Köping-Höggard M., Tubulekas I., Guan H., Edwards K., et al., Chitosan as a nonviral gene delivery system. Structure-property relationships and characteristics compared with polyethylenimine in vitro and after lung administration in vivo, Gene Therapy, 2001, 8, 11081121. 


\section{Figure legends}

Figure 1: Calibration of the dot-blot quantitation for 5-bromo-2-deoxyuridine (BrdU)incorporation in vivo. A: various amounts (15-450 ng) of pDNA or PCR product containing either thymidine or BrdU were dot-blotted on a nitrocellulose membrane, and the incorporated BrdU was immunochemically visualized. Lane 1, BrdU-labelled pDNA; lane 2, unlabelled pDNA; lane 3, BrdU-labelled PCR product; lane 4, unlabelled PCR product; lane 5, BrdU-labelled pDNA complexed with PEI; lane 6, BrdU-labelled pDNA complexed with PEI-rhodamine; lane 7, unlabelled pDNA complexed with PEI; lane 8, unlabelled pDNA complexed with PEI-rhodamine .

B: Calibration curve created from densitometric analysis of the calibration dot blots (weighted linear regression: $\left.\mathrm{y}=2.41 \times 10^{7} \log _{10}(\mathrm{x})-3.12 \times 10^{8} ; \mathrm{R}^{2}=0.970 ; \mathrm{n}=5\right)$

Figure 2: Intracellular distribution of BrdU-labelled plasmids after transfection. Panels A, B: CHO $3 \mathrm{~h}$ post electroporation, panels C, D: CHO cells $3 \mathrm{~h}$ after transfection with PEI. For the measurement cells were fixated with $p$-formaldehyde and incubated with anti-BrdU antibody (panels B, D). The nuclei were counterstained with Hoechst 33258 (panels A, C). The arrow indicates large aggregates, which could typically be resolved into several small aggregates by analysing the slide with phase contrast.

Figure 3: Representative single confocal slices of transfected $\mathrm{CHO}$ cells. The plasmids were visualized by immunofluorescence (anti-BrdU antibody (clone BU33)). Panel A: CHO cells after electroporation; panel B: CHO after PEI-mediated transfection. Each bar represents 20 $\mu \mathrm{m}$. 


\section{Tables}

Table 1

Optical densities, maximum growth rates, and doubling times determined after 5 hours of growth in the indicated growth medium (LB medium supplemented with $5 \mathrm{mM} \mathrm{MgCl}_{2}, 0.01 \%$ Diaminopimelic acid, $0.5 \%$ glucose, and $40 \mathrm{mg} / \mathrm{L}$ thymidine or BrdU respectively). Starting $\mathrm{OD}_{600}$ in all cases was 0.02. Pre-cultures were all in the presence of thymidine.

\begin{tabular}{lcccc}
\hline Composition of the growth medium & & End $\mathbf{O D}_{\mathbf{6 0 0}}$ & $\boldsymbol{\mu}_{\max }\left(\mathbf{h}^{-1}\right)$ & $\mathbf{t}_{\mathbf{d}}(\mathbf{h})$ \\
\hline Thymidine & $40 \mathrm{mg} / \mathrm{L}$ & 2.40 & 1.20 & 0.58 \\
& & & & \\
Bromodeoxyuridine & $40 \mathrm{mg} / \mathrm{L}$ & 0.21 & 0.51 & 1.37 \\
& $80 \mathrm{mg} / \mathrm{L}$ & 0.19 & 0.51 & 1.37 \\
& $120 \mathrm{mg} / \mathrm{L}$ & 0.21 & 0.44 & 1.57 \\
& & & & \\
Thymidine + Bromodeoxyuridine* & $0 \mathrm{mg} / \mathrm{L}$ & 2.44 & n.d. & n.d. \\
& $40 \mathrm{mg} / \mathrm{L}$ & 2.33 & n.d. & n.d. \\
& $80 \mathrm{mg} / \mathrm{L}$ & 0.1 & n.d. & n.d. \\
& $120 \mathrm{mg} / \mathrm{L}$ & 0.2 & n.d. & n.d. \\
\hline
\end{tabular}

*: medium contained $40 \mathrm{mg} / \mathrm{L}$ thymidine and incubation was overnight.

n.d. not determined 


\section{Amount of DNA (ng/dot)}

$\begin{array}{llllll}456 & 227 & 114 & 57 & 28 & 14\end{array}$

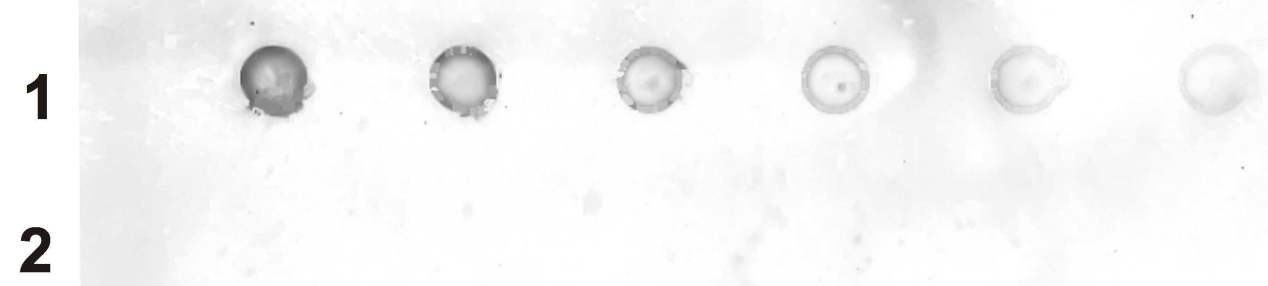

4

5

6

7

8

Figure 1A ( Jérôme et al.) 


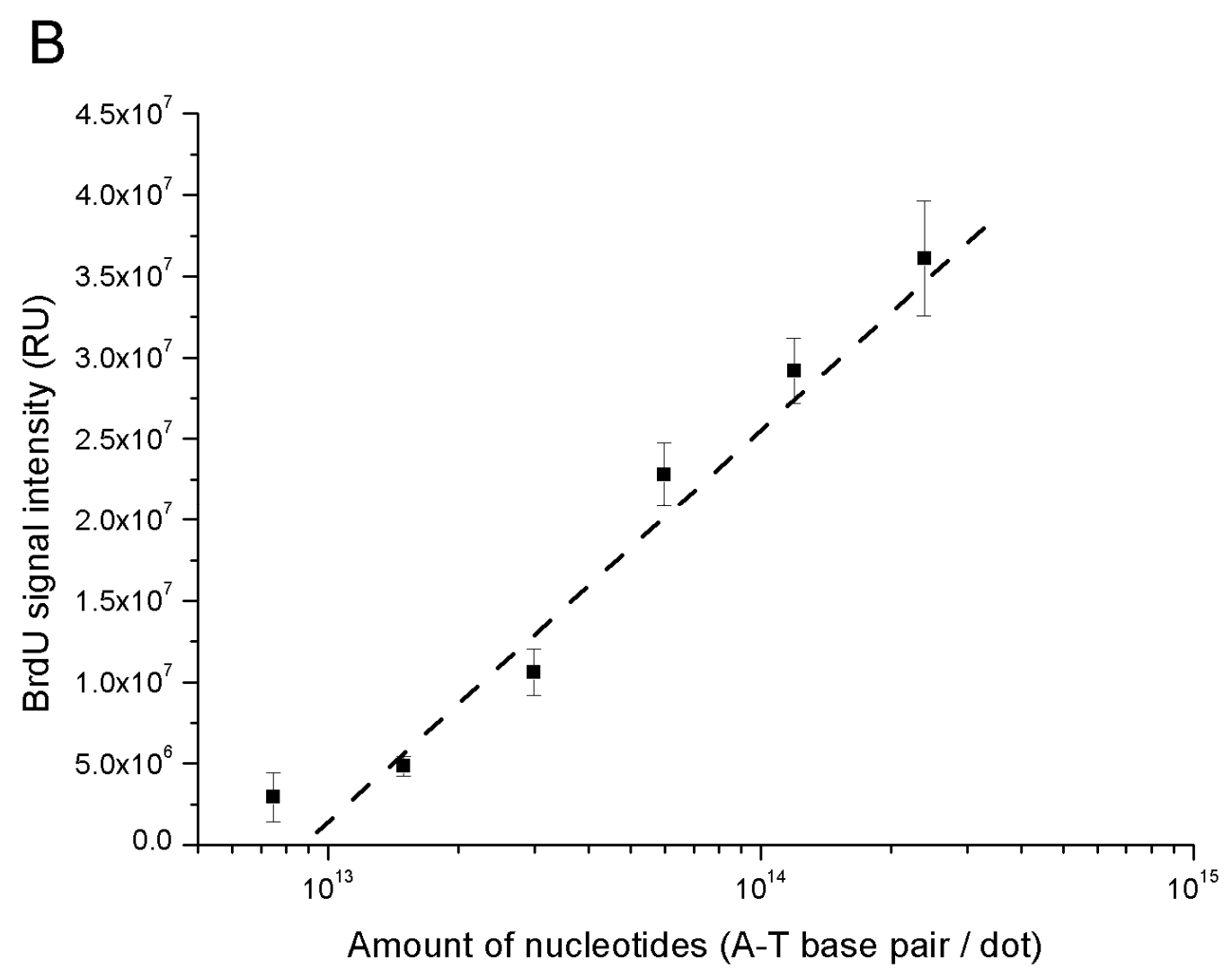

Figure 1B (Jérôme et al.) 

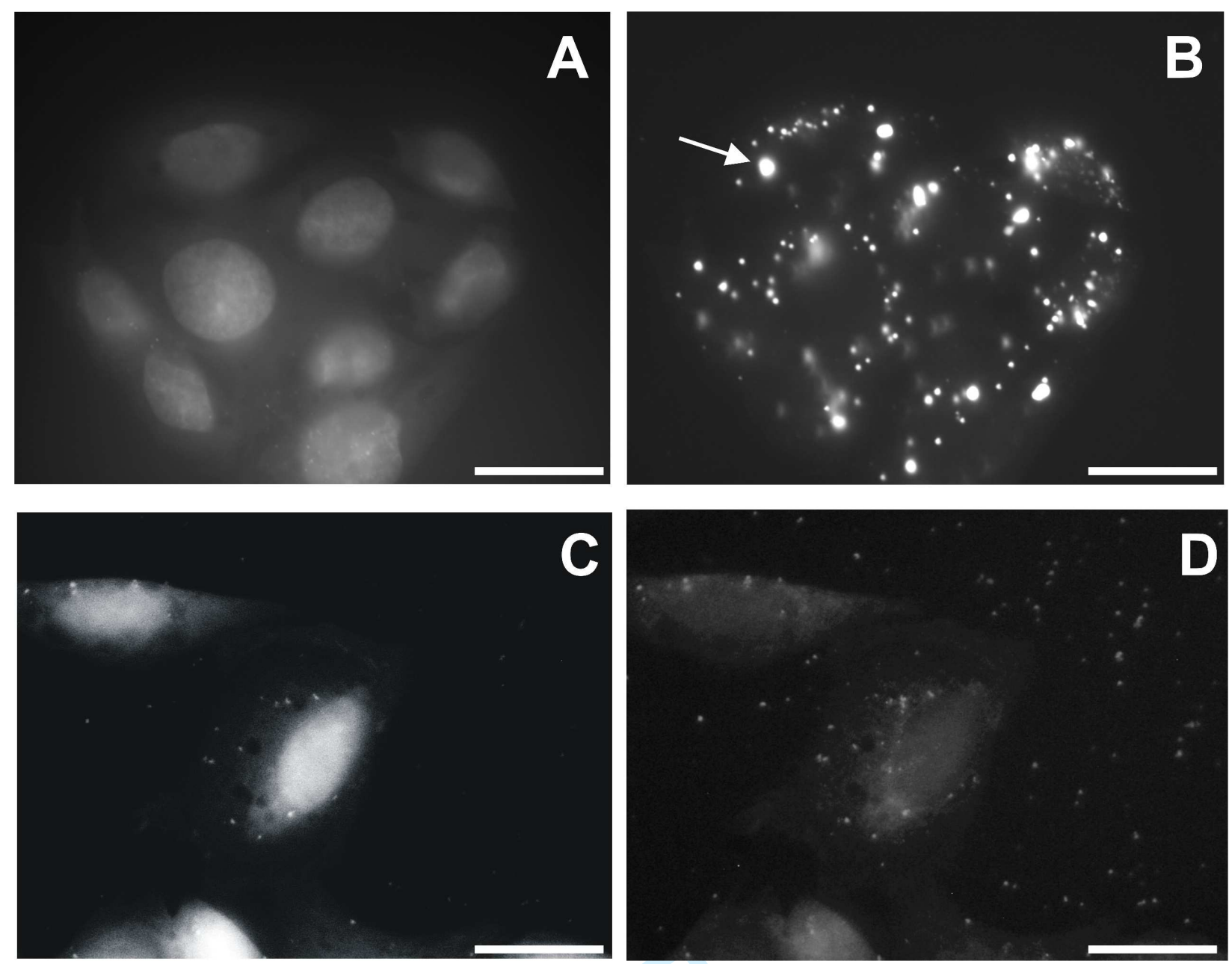

Figure 2 (Jérôme et al.) 


1
2
3
4
5
6
7
8
9
10
11
12
13
14
15
16
17
18
19
20
21
22
23
24
25
26
27
28
29
30
31
32
33
34
35
36
37
38
39
40
41
42
43
44
45
46
47
48
49
50
51
52
53
54
55
56
57
58
59
60
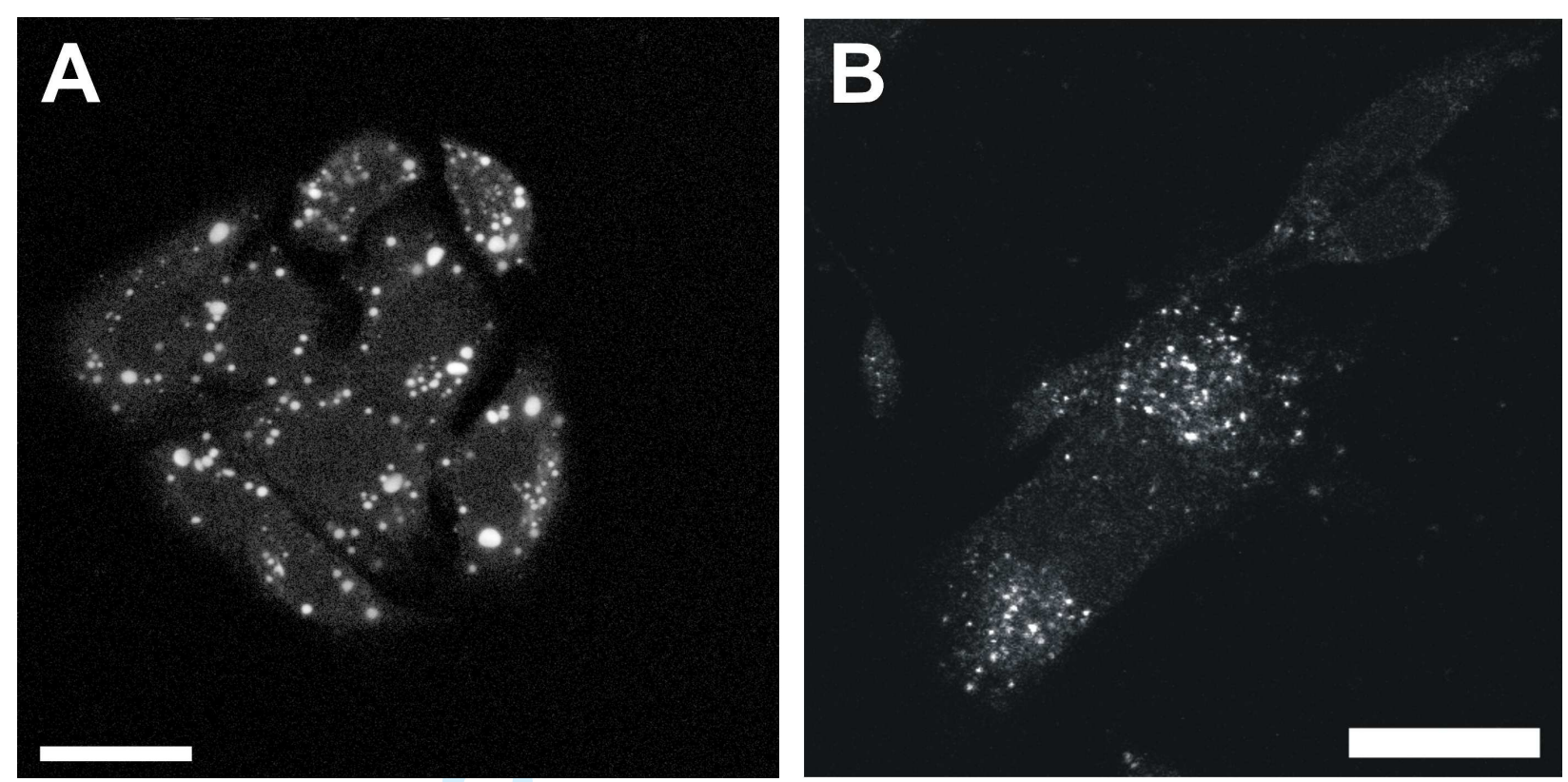

Figure 3 (Jérôme et al.) 